\title{
Mentoring: Ir ou não Ir, eis a Questão: um Estudo Qualitativo
}

\author{
Mentoring: to Attend or not to Attend, That is \\ the Question: a Qualitative Study
}

Patrícia Lacerda Bellodi Rachel Chebabol

Silvia Itzcovici Abensur ${ }^{I}$ Milton de Arruda Martins

\section{PALAVRAS-CHAVE: \\ - Tutoria \\ - Estudantes de Medicina \\ - Educação Médica}

\section{KEYWORDS:}

- Mentorship

- Students, Medical

- Education, Medical

Recebido em: 22/11/2010 Aprovado em: 24/01/2011 REVISTA BRASILEIRA DE EDUCAÇÃO MÉDIC

\section{RESUMO}

Para melhor compreender a adesão dos alunos a um Programa de Mentoring, o Programa Tutores FMUSP, este estudo qualitativo explorou as razões apresentadas pelos estudantes em relação ao seu envolvimento com a atividade, no período 2004-2005, antes e depois de mudanças estruturais no programa (inserção da atividade na grade horária). Os estudantes avaliam anualmente o programa por meio de um questionário estruturado - "O Tutorando". Nele, uma questão específica sobre adesão é apresentada e foi analisada neste estudo. A análise dos resultados mostra que a troca de experiência entre alunos de diferentes anos, mediada por um tutor habilidoso, promove uma visão ampliada do curso e da profissão e motiva os alunos a participarem mais do programa. Tutores que se desligam do programa, agendamento irregular dos encontros, comunicação não efetiva, discussão de temas desinteressantes contribuem para uma baixa adesão. A inserção do programa na grade horária oficial resolveu importantes problemas, mas muitos alunos ainda preferem usar o tempo do Mentoring para outras atividades acadêmicas ou necessidades pessoais. O mentoring informal e grupos com uma dinâmica ruim também justificam, para os alunos, uma menor adesão. O sucesso de um Programa de Mentoring, no que diz respeito à adesão dos alunos, mostra estar vinculado não apenas a uma estrutura adequada, mas também às características pessoais e valores dos participantes.

In order to better understand students' adherence to the Mentoring Program at the School of Medicine, University of São Paulo (FMUSP), this qualitative study explored the reasons expressed by students for their involvement in the activity in 2004-2005, before and after structural changes in the program (inclusion of the mentoring program in the course hours). Students perform an annual assessment of the program through a structured questionnaire: "The Mentoree". This includes a specific question on attendance in the program, analyzed in this study. The findings show that exchange of experiences between students from different years, as mediated by a skillful mentor, promotes an expanded view of the course and the profession and motivates students to participate more in the program. Mentors that leave the program, irregular scheduling of meetings, ineffective communication, and discussion of uninteresting themes contribute to low adherence to the program. Inclusion of the program in the official course hours solved important problems, but many students still prefer to use the mentoring time for other academic activities or personal needs. Informal mentoring and groups with poor dynamics also explain limited participation (in the students' eyes). A mentoring program's success, as measured by students' participation, proves to be linked not only to an adequate structure, but also to the participants' personal characteristics and values. 


\section{INTRODUÇÃO}

O caminho de formação do futuro médico não é apenas extenso em relação ao tempo, mas também intenso pelas vivências experimentadas durante todo o processo de aprendizagem. São seis longos anos em que o aluno entra em contato com um vasto conjunto de informações, aprende técnicas e desenvolve habilidades que, ao final, deverão, em conjunto, ser expressas em termos de adequadas competências clínicas e humanísticas. Do ponto de vista emocional e pessoal, esse não é um caminho tranquilo e, em vários e diferentes estudos a respeito do bem-estar do futuro médico, os níveis de sofrimento psíquico dos estudantes de Medicina ultrapassam a média da população ${ }^{1}$.

Considerando esse contexto, ações institucionais dirigidas ao bem-estar do aluno de Medicina têm sido desenvolvidas em muitas escolas médicas, dentro e fora do Brasil, tais como: serviços de apoio psicológico, psiquiátrico e pedagógico; apadrinhamento de calouros por veteranos; e programas de mentoring, nos quais um profissional experiente acompanha e orienta o jovem aluno ao longo de sua formação, oferecendo suporte pessoal e promovendo o desenvolvimento profissional. Esses programas são exemplos de intervenções possíveis dentro da proposta de oferecimento de uma rede de suporte ao aluno durante a formação médica ${ }^{2,3}$.

Entretanto, ao mesmo tempo em que os estudos evidenciam a insalubridade psicológica durante a formação médica ${ }^{4}$ ${ }^{5}$ e apontam a relação entre qualidade de vida ruim durante $o$ curso e a ausência de suporte durante a formação ${ }^{6}$, mostram também uma série de barreiras à utilização desses recursos sejam eles de caráter especializado (serviços de psicoterapia) ou de caráter amplo e focados no desenvolvimento global do estudante (programas de mentoring).

Entre os alunos de Medicina, além do estigma social, das preocupações quanto à privacidade, das dificuldades de tempo e acesso aos recursos, destacam-se aspectos como a resistência em reconhecer que necessitam de ajuda, a tendência em minimizar os sintomas, a se autodiagnosticar e a buscar ajuda informal $^{7-10}$

Em relação aos programas de mentoring, estudos da área mostram que, apesar dos benefícios potenciais desse tipo de relação, há uma relativa falta de interesse por parte dos estudantes de Medicina em encontrar um mentor, mesmo quando apresentam dificuldades durante o curso ${ }^{11}$. Na Universidade da Califórnia, em estudo que investigou as relações informais de mentoring entre 232 estudantes do $3^{\circ}$ e $4^{\circ}$ anos de Medicina constatou que apenas $36 \%$ dos alunos procuraram auxílio de um mentor, apesar de mais de $90 \%$ reconhecerem a importância de um suporte como o mentoring ${ }^{12}$.
No Brasil, programas de mentoring são experiências mais recentes nas estruturas curriculares e nas avaliações já realizadas, os coordenadores dessas iniciativas indicam aspectos positivos e negativos das experiências ${ }^{3}$.

Há o reconhecimento da pertinência da atividade e clareza da satisfação experimentada por tutores e alunos quando, na troca de experiência, ocorrem discussões interessantes e maior proximidade entre eles. Entretanto, são observadas dificuldades referentes à disponibilidade de tempo e à falta de interesse dos envolvidos em participar da atividade.

A adesão dos alunos, especialmente, tem sido alvo de preocupação dos coordenadores, uma vez que muitos tutores, devido à reduzida participação dos estudantes, relatam frustração das expectativas iniciais e desânimo para continuar no programa. Para eles, é difícil motivar alunos com maior resistência em participar do programa e aumentar a adesão de alunos com dificuldades em participar da atividade ${ }^{13}$.

Sabe-se que o mentoring é uma relação de mão dupla na qual o potencial do mentor em engajar seu aluno em interações mais complexas e satisfatórias cresce à medida que o jovem (aluno) também responde ao potencial positivo da relação ${ }^{14}$.

Nesse sentido, a questão do envolvimento do aluno com a proposta é crucial não apenas para o sucesso da relação em si, mas também, de forma ampliada, para a permanência dos programas de mentoring ao longo do tempo.

\section{O Programa Tutores FMUSP e o Envolvimento dos Alunos}

O programa de mentoring da Faculdade de Medicina da Universidade de São Paulo, Programa Tutores FMUSP, introduzido em 2001, estabeleceu para os alunos da faculdade a figura de um tutor (com papel de mentor) que, por meio de encontros regulares para discussão de aspectos pessoais, acadêmicos e profissionais, acompanha seu desenvolvimento ao longo do curso. O programa busca, por meio dessa atividade, aproximar professores e alunos, promover a troca organizada de experiência entre os alunos dos diferentes anos, identificar problemas no curso e na formação, e contribuir para uma formação integral do futuro médico ${ }^{3}$.

O programa conta com um grupo de tutores responsáveis, em média, por um grupo de 12 a 14 alunos. Todos os alunos da FMUSP (1.080 no total) têm um tutor de referência, sua participação no programa é voluntária e estimulada por meio de créditos, registro no histórico escolar e certificado ao final do curso, quando comparecem a no mínimo $70 \%$ dos encontros realizados.

Os tutores, professores da faculdade ou médicos do hospital-escola, são selecionados a partir do seu envolvimento com a graduação, de sua disponibilidade de tempo e de ca- 
racterísticas pessoais, como: empatia, interesse e bom relacionamento com os alunos. Participam de treinamento inicial e de supervisões periódicas com profissionais da área da saúde mental (psicólogos e psiquiatras), para a discussão de sua experiência junto aos alunos nos grupos de tutoria. O programa conta ainda com o suporte de uma equipe técnica, e todos os envolvidos na atividade (tutores, alunos e supervisores) têm, por meio de seus representantes, participação nas reuniões da coordenação geral.

Tutores e alunos avaliam regularmente o programa e os encontros por meio do registro sistemático de suas atividades (Diário do Tutor) e de questionários (O Tutorando), respectivamente. Aspectos qualitativos e quantitativos são abordados nesses instrumentos de avaliação, em especial aqueles que dizem respeito à satisfação, adesão e impacto da atividade.

Apesar do cuidadoso planejamento inicial envolvendo professores e alunos preocupados com o estabelecimento de uma estrutura e dinâmica adequadas, a adesão média dos alunos às reuniões, nos primeiros anos, compôs uma curva decrescente: 50\% em 2001; 41\% em 2002; 35\% em 2003 e 30\% em 2004 , frustrando os tutores em suas motivações iniciais.

Devido a essa queda no envolvimento dos alunos, mudanças foram feitas no programa a partir das avaliações deles, nas quais se queixavam, especialmente, do horário dos encontros (horário de almoço ou final da tarde, depois das aulas).

Em 2005, o Programa Tutores foi incluído na grade horária oficial da escola, não mais requerendo tempo extra dos alunos para a atividade. Além disso, os encontros, que antes eram acordados pelos tutores e seus alunos, passaram a ser agendados pela coordenação do programa. Foram determinados 10 encontros anuais, um por mês, no período das $10 \mathrm{~h}$ às $12 \mathrm{~h}$, momento em que não era prevista a realização de outras atividades acadêmicas na escola (aulas, iniciação científica, etc.) ou no hospital (com dispensa dos internos). O crédito associado à atividade se tornou parte importante do total de créditos das disciplinas optativas a serem cursadas.

Como resultado, a adesão dos alunos aumentou para 53\% em 2005. Esse aumento foi importante, mas menos significativo que o esperado pela coordenação do programa e pelos tutores, continuando, assim, a ser uma questão de difícil, porém necessária, abordagem ${ }^{15}$.

Para melhor compreender a adesão dos alunos ao Programa Tutores FMUSP e contribuir com outras experiências no campo do mentoring, este estudo, de caráter qualitativo, tem por objetivo explorar e discutir as razões apresentadas pelos alunos quanto ao seu envolvimento com a atividade, considerando especialmente o período de 2004-2005, antes e depois das mudanças realizadas.

\section{MÉTODO}

Para responder ao objetivo do estudo, foram analisadas as respostas dos alunos a uma questão específica do questionário utilizado por eles, periodicamente, para a avaliação do Programa Tutores.

Esse questionário, denominado "O Tutorando", é distribuído anualmente a todos os alunos da escola e tem como objetivo avaliar satisfação (com o tutor, o grupo e o programa como um todo), impacto da atividade (mudanças) e, qualitativamente, abordar as razões de adesão do aluno ao programa. É um instrumento estruturado, composto por questões abertas e fechadas, assim como por escalas de cinco pontos tipo Likert.

O instrumento é distribuído em sala de aula e seu preenchimento é voluntário e anônimo. É garantido ao aluno que o resultado das avaliações somente será divulgado de forma global e jamais serão identificados os respondentes.

A adesão ao programa é abordada em O Tutorando por meio de um item específico, assim apresentado:
Você na Tutoria
Adesão (assinale a alternativa que melhor o representa):
( ) Fui à maioria dos encontros.
( ) Fui às vezes
( ) Fui apenas uma ou duas vezes e depois
( ) Não fui. deixei de ir
Por quê?

$\mathrm{Na}$ análise dos dados deste estudo, cada um desses diferentes graus de adesão constitui um eixo de análise e, dentro deles, as respostas dadas pelos alunos à questão aberta foram analisadas segundo a técnica de análise de conteúdo ${ }^{16}$, que envolve leitura flutuante e repetida das informações, identificação das unidades de significado e construção de categorias.

\section{RESULTADOS}

\section{Respondentes}

Dos 1.080 alunos da faculdade, 661 (61\%) responderam ao questionário em 2004, assim distribuídos: $58 \%$ do sexo masculino; $41 \%$ do $1^{\circ}$ e $2^{\circ}$ anos; $29 \%$ do $3^{\circ}$ e $4^{\circ}$ anos; e $30 \%$ do internato.

Em 2005, 751 (70\%) alunos responderam ao instrumento, sendo novamente $58 \%$ do sexo masculino e, em relação ao ano acadêmico, $37 \%$ do $1^{\circ}$ e $2^{\circ}$ anos; $35 \%$ do $3^{\circ}$ e $4^{\circ}$ anos; e $27 \%$ do internato.

A distribuição dos respondentes quanto a seu grau de envolvimento com o programa encontra-se na tabela 1 : 


\section{TABELA 1}

Distribuição dos alunos em relação às diferentes categorias de adesão, antes (2004) e depois das mudanças (2005).

\begin{tabular}{lcccc}
\hline \multirow{2}{*}{ Adesão ao Programa } & \multicolumn{2}{c}{2004} & \multicolumn{2}{c}{2005} \\
\cline { 2 - 5 } & $n$ & $\%$ & $n$ & $\%$ \\
\hline \hline Fui à maioria & 266 & $40 \%$ & 528 & $70 \%$ \\
Fui às vezes & 134 & $20 \%$ & 119 & $16 \%$ \\
Fui apenas uma ou duas vezes & 86 & $13 \%$ & 85 & $11 \%$ \\
Não fui & 39 & $6 \%$ & 15 & $2 \%$ \\
Sem resposta & 136 & $21 \%$ & 4 & $1 \%$ \\
\hline Respondentes & 661 & & 751 & \\
\hline
\end{tabular}

\section{EIXOS DE ANÁLISE E CATEGORIAS}

\section{O aluno que vai à maioria dos encontros}

O aluno que vai sempre ou à maior parte dos encontros não mostrou diferenças em suas razões antes e depois das mudanças. Esse grupo de alunos, composto em sua maioria por alunos dos dois primeiros anos, é aquele que valoriza a atividade para sua formação e reconhece seus benefícios.

"Acredito que seja importante para a formação durante a vida acadêmica." (1ํano, 2004)

"Acho o programa muito útil, interessante e fundamental." (3a ano, 2004)

"Acho a tutoria importante para minha formação, como forma de orientação acadêmica." (4ํano, 2005)

"Acredito ser importante para minha formação e a de meus colegas." (5aano, 2005)

Para esses alunos, a troca de experiências promovida pelo programa é útil e enriquecedora, pois amplia sua visão do curso e contribui com sugestões práticas sobre como lidar com o cotidiano da vida acadêmica.

"O grupo de tutoria me ajuda a conhecer a opinião dos veteranos e, assim, consigo aprender muita coisa sobre o curso, o que eu devo fazer e quando fazer, por exemplo, em relação às ligas." (1o ano, 2004)

"Gosto da convivência e da troca de experiência sobre assuntos da faculdade, da área médica e da vida do médico com meus colegas de outros anos e com meu tutor." (3o ano, 2004) "Gosto de compartilhar experiências; gosto de ouvir sobre as experiências dos veteranos. “( $3^{\circ}$ ano, 2005)

"Porque considero essencial para meu bom aproveitamento da faculdade trocar experiências com pessoas que já passaram por ela." (1aano, 2005)
Além disso, independentemente das mudanças realizadas, um tutor comprometido e interessado, com habilidade para orientar e conduzir o grupo, é muito valorizado pelos jovens.

\footnotetext{
"Porque é um ambiente agradável, os assuntos são bons, e a tutora está sempre bastante disposta a nos dar dicas, ajudar, orientar." (3a ano, 2004)

"Gosto muito das reuniões. Os assuntos são interessantes; admiro meu tutor como profissional e gosto de ouvir suas opiniões." (3oano, 2004)

"A tutora é muito boa e o grupo se entrosa muito bem, ela estimula todos a falar e nunca faltam assuntos." ( 6 - ano, 2005) "Gosto muito da tutoria, gosto muito da minha tutora. Ela é extremamente interessante, interessada e conduz muito bem." (1a ano, 2005)
}

Apenas três alunos, em 2005, mencionaram em suas respostas a inclusão da atividade na grade horária:

"Além de estar na grade horária, é agradável compartilhar experiências." ( $1^{-}$ano, 2005)

"Pelo horário reservado." (6ำ ano, 2005)

"Porque sou dispensado da aula." (5o ano, 2005)

Alguns alunos, em suas respostas, mostram ter interpretado a mudança como "obrigatoriedade".

\footnotetext{
"Basicamente porque é obrigatório." (4⿳a ano, 2005)

"Porque é obrigatório." (4ํano, 2005)

"Atividade obrigatória e porque pode ser interessante." (6 ano, 2005)

"Por ser obrigatório e ser do meu agrado." (5aano, 2005)
}

Apenas um único aluno, nos dois anos analisados, referiu-se à Tutoria como algo que valorizará seu currículo no futuro.

Pelo currículo, para aumentar a chance de ser aprovado na residência. (6o ano, 2005)

\section{2. $O$ aluno que vai às vezes}

Os alunos que comparecem às vezes são aqueles que justificam sua participação irregular, seja antes ou depois das mudanças, pela concorrência de outras atividades, às quais, geralmente, atribuem maior valor e "disputam" o seu tempo.

Em 2004, antes das mudanças, predominavam nesse grupo os alunos do internato; depois, em 2005, os alunos do $3^{\circ}$ e $4^{\circ}$ anos foram aqueles que mais participaram "às vezes" do programa. 
“Não compareço quando a reunião é próxima a uma prova ou tenho algum trabalho de pesquisa para terminar." (2o ano, 2004)

"Não tenho ido às reuniões devido ao grande número de atividades curriculares e extracurriculares de que participo. Além disso, o $4^{\circ}$ ano de Medicina é bem puxado e estressante." (4⿳⺈⿴囗十一 ano, 2004)

"Este ano (internato) foi bastante difícil estar presente, pelos horários, plantões e distância HU-HC." (5a ano, 2004)

"Durante o 6a ano não consegui conciliar os horários de Tutoria (almoço) com as atividades do internato." (6-ano, 2004) "Sempre há alguma atividade no mesmo horário: cirurgias, aulas, visitas." (6o ano, 2004)

"Estava com tarefas mais importantes no meu laboratório." (3a ano, 2005)

"Problemas de horário com a pesquisa científica." (3o ano, 2005)

"Porque tenho atividade no horário da reunião que nem sempre posso faltar. Teoricamente, não poderia ter uma atividade, mas é necessário." (4o ano, 2005)

"Porque tenho outras atividades que são prioridades para mim." (4⿳⺈ ano, 2005)

"Alguns estágios não dispensam." (6-ano, 2005)

Antes das mudanças, em 2004, esse grupo justificava sua menor adesão referindo dificuldades de deslocamento (da Cidade Universitária até o local do encontro, na FMUSP) e, especialmente, queixava-se do fato da atividade ocorrer no horário livre para almoçar ou ir para casa, no final da tarde.

"Os horários da tutoria são muito ruins, perco almoço ou outros compromissos." (1a ano, 2004)

"Horário no almoço, grade horária apertada." (2aa ano, 2004)

"As reuniões são marcadas para o horário de almoço e se estendem até quase 2 horas, o que atrapalha para a pontualidade nas aulas da tarde que são dadas na Cidade Universidade." (3o ano, 2004)

"Meu horário de almoço não é tempo livre!" (5a ano, 2004)

"Às vezes não é possível sair da Enfermaria/Ambulatório ou até do Centro Cirúrgico para ir às reuniões na hora do almoço." (5oano, 2004)

A inclusão da atividade na grade oficial, em 2005, diminuiu as queixas a respeito do deslocamento e do horário de almoço ou fim de tarde.

No entanto, com a dispensa das atividades curriculares, o tempo para a Tutoria começou a ser usado como tempo livre para necessidades pessoais (descansar, dormir ou atividades diárias, por exemplo) ou continuou a ser destinado, muitas vezes, para atividades acadêmicas consideradas mais interessantes (procedimentos no internato, iniciação científica nos anos anteriores).
"Algumas vezes en esquecia ou estava muito cansada." (4º ano, 2005)
"Porque a tutoria é de manhã e não é muito legal a ideia de ter que acordar em um dia que poderia dormir até mais tarde."

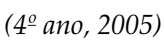
"Na maioria das vezes tenho dificuldade para acordar, já que é o único dia com a manhã livre." (4oano, 2005)
"Tenho a vida bastante corrida e acabo por me servir do tempo da tutoria para outros fins." (6o ano, 2005)
"Estava com tarefas mais importantes no meu laboratório." (3a ano, 2005)
"Porque, como sou interna, muitas vezes tive que resolver algo de meus pacientes." (5⿳a ano, 2005)
"Porque eu estava acompanhando procedimentos (exames, cirurgias) de pacientes, mesmo tendo sido dispensado dessas atividades, acho muito importante a evolução desses pacien- tes." (6a ano, 2005)
"Dou mais preferência às atividades da faculdade (internato). Se eu estou em um ambulatório interessante, prefiro não ir." (5a ano, 2005)

Uma dinâmica de grupo ruim, com discussões desinteressantes, também foi apontada como razão para o comparecimento irregular, antes ou depois das mudanças:
"As reuniões são desinteressantes, não há entrosamento do grupo." (3o ano, 2004)
"Principalmente porque considero os assuntos das reuniões repetitivos." (4o ano, 2004)
"Como vão poucas pessoas e não há uma discussão efetiva, fico desestimulado a retornar." (3o ano, 2004)
"Acho as discussões repetitivas, na verdade, poucas pessoas falam." (5a ano, 2005)
"As reuniões são pouco produtivas, as discussões ficam sem- pre na mesma." ( 4 o ano, 2005)
"Sempre os mesmos temas, conselhos e discussões." (4ํano, 2005)

\section{3. $O$ aluno que vai apenas uma ou duas vezes}

Temas desinteressantes e grupo com poucos alunos, o agendamento irregular dos encontros e dificuldades de comunicação foram as razões apresentadas pelos alunos que deixaram de comparecer depois dos primeiros encontros, em 2004. Nesse ano, predominavam no grupo os alunos do $1^{\mathrm{o}}$ e $2^{\mathrm{o}}$ anos.

\footnotetext{
"Achei o grupo pouco receptivo e trata de temas pouco interessantes." ( $2^{\circ}$ ano, 2004)

"Temas desinteressantes, pouquíssimas pessoas." (2ำ ano, 2004)
} 
"Percebi pouca participação no meu grupo. Alunos de outros anos não compareciam, assuntos discutidos causaram pouca motivação." (6⿳a ano, 2004)

"Não tem muitas reuniões, as que tiveram eu só fiquei sabendo tarde." (1a ano, 2004)

"Após duas reuniões não recebi mais e-mail dizendo a data, horário e local das reuniões." (1ํo ano, 2004)

"A tutora mudou o dia dos encontros, da última vez não pude ir porque abri meu e-mail um dia depois da reunião." ( $2^{\underline{o}}$ ano, 2004)

"Tivemos poucos encontros no ano passado e, este ano, o tutor marcou um único encontro nas férias." (6ª ano, 2004)

Em 2005, entre os respondentes, predominaram no grupo os alunos do $3^{\circ}$ e $4^{\circ}$ anos.

Com a inclusão da atividade no calendário anual e a determinação dos dez encontros anuais, a coordenação do programa passou a avisar os alunos das datas das reuniões. Assim, as queixas sobre comunicação e agendamento dos encontros diminuiu significativamente. No entanto, os alunos desse grupo destacaram a falta de relevância da atividade para eles.

"Acho desnecessário e chato." (1ํo ano, 2005)

"Não acho a atividade de tutoria importante." (2ano, 2005)

"Acredito que não me acrescenta nada de relevante." (3a ano, 2005)

"Não acho que é tão produtivo e construtivo como dizem." (5o ano, 2005)

Entre esses alunos, tanto em 2004 quanto em 2005, encontram-se também aqueles que relatam já terem, naturalmente, um grupo de amigos com os quais têm maior vínculo e acesso às informações e orientações que necessitam sobre o curso - o chamado mentoring informal.

"Frequento a Atlética e tenho amigos de todos os anos, adquiro as informações que quero nesse ambiente mais natural." (2ano, 2004)

"Chato, prefiro conversar sobre esses assuntos com amigos." (4⿳⺈⿴囗十一 ano, 2004)

"Porque é chato ter que discutir com pessoas que eu nem conheço assuntos que discuto muito mais a fundo com meus amigos." (3o ano, 2005)

"Esse tipo de interação (objetivada pela tutoria) eu tenho normalmente com os colegas, seja na Atlética, Academia, CAOC, Faculdade, etc." (5a ano, 2005)

\section{O aluno que não vai}

Houve poucos respondentes nessa categoria tanto em 2004 quanto em 2005, mas suas respostas permitiram identificar al- gumas razões importantes, do ponto de vista qualitativo. Em 2004, predominaram nesse grupo os alunos do internato; em 2005 predominaram os alunos do $3^{\circ}$ e $4^{\circ}$ anos.

O grupo de alunos ausentes, antes das mudanças, justificava enfaticamente sua não adesão por fatores ligados a seus tutores, seja porque estes haviam se desligado do programa, seja porque não agendavam regularmente os encontros nem se comunicavam com os alunos.
"Minha antiga tutora abandonou o projeto, fui remanejado para outro grupo cujo tutor, pelo que sei, nunca marcou uma reunião." (5oano, 2004)
"Que tutor? O tutor sumiu e isso porque é o $30^{\circ}$ tutor!!!" (2aa ano, 2004)
"Porque não sei quem é meu tutor, todo ano muda, e ele nun- ca me mandou um e-mail." (4⿳⺈ ano, 2004)
"Não fui porque o grupo mudou de tutor e, embora tenha en- trado em contato com o professor a fim de saber onde seriam as reuniões, não obtive resposta." (5o ano, 2004)

Depois das mudanças realizadas, os ausentes, assim como os alunos de outras categorias de adesão, também justificaram sua não participação por conta de outras atividades mais interessantes.

\footnotetext{
"Faço iniciação científica e lidero um projeto que toma muito tempo de mim." (2a ano, 2005)

"Não consegui. Tinha que estudar; tinha que dormir." (1 ${ }^{\circ}$ ano, 2005)
}

Um dos incentivos oferecidos pelo programa, o crédito, foi referido por um aluno e considerado não suficiente para motivá-lo.

"Sempre aparecia algo para fazer. Por um crédito, fico com
minha iniciação que vale cinco." (3a ano, 2005)

Nesse grupo de alunos, há também aqueles que justificam a não adesão por considerarem que a atividade só teria sentido para aqueles sem apoio de amigos ou familiares.

"A tutoria serve para quem não tem amigos ou pais." (4⿳亠丷厂 ano, 2005)

"Serve só para quem não tem amigos." (4⿳亠口冖 ano, 2005)

\section{DISCUSSÃO E CONCLUSÃO}

Este estudo, ao explorar as razões de adesão de estudantes de Medicina ao Programa Tutores FMUSP, mostra a natureza complexa de um programa de mentoring. 
O que torna um sistema "complexo", segundo Grove", é a introdução de elementos humanos, como são as relações, as paixões, a liberdade de fazer escolher. Diz esse autor que quanto mais esses elementos impactam o funcionamento de um sistema, mais complexo ele será.

A análise das razões dos alunos em "ir ou não ir" ao programa mostrou o quanto esses elementos humanos, de caráter subjetivo, estão presentes e acabam por se articular com elementos externos, derivados da estrutura e dinâmica do programa, da faculdade e da própria formação médica.

Em 2004, antes das mudanças, os alunos justificavam sua menor adesão ou não adesão dirigindo-se fortemente àquilo que se encontrava "fora dele", por exemplo, com questões como: a Tutoria no horário de almoço atrapalhava suas outras atividades extracurriculares; os tutores faltavam e não se comunicavam para avisar sobre os próximos encontros; os encontros eram agendados de forma inconstante; era difícil se deslocar até o local do encontro na faculdade estando na Cidade Universitária.

Sem dúvida, todas essas queixas são relevantes, e avaliações de outros programas mostram a importância desse aspecto. Malik ${ }^{18}$, em sua avaliação do Programa de mentoring de Dundee, assim como Cottrell et $\mathrm{al}^{19}$, no London Hospital Medical College, mostraram que a previsibilidade dos encontros encontra-se relacionada a um resultado de sucesso no programa.

Esses mesmos estudos ${ }^{18,19}$ mostram também a importância, na comunicação, de um papel ativo do tutor. Alunos que são procurados por seus tutores mostram-se mais satisfeitos com o programa, pois aqueles reconhecem nestes que assim o fazem maior comprometimento e valorização da própria atividade do mentoring.

A sobrecarga de atividades, curriculares e extracurriculares dos estudantes, característica da formação médica atual, revela algo de natureza paradoxal: a própria natureza da formação médica, que aponta para a necessidade desse tipo de suporte, acaba por dificultar bastante o estabelecimento de relações continuadas de mentoring. Uma agenda repleta de atividades deixa pouco espaço para encontros contínuos, como foi mostrado por Woessner e colegas ${ }^{20}$ em sua avaliação de um programa de mentoring alemão.

Em 2005, essas demandas dos alunos foram consideradas e atendidas pela coordenação do programa da Universidade do Estado de São Paulo, e um novo enquadramento para os encontros foi estabelecido: agora, o aluno tem, de forma regular e estabelecidos em um calendário já no início do ano, encontros mensais dentro de sua grade horária. Atividades curriculares e extracurriculares deixam de ser realizadas ou são aconselhadas a não ocorrerem no período de tempo do mentoring. No internato, os alunos são dispensados de suas atividades no hospital. Sem dúvida, a mensagem de que a escola considera importante a Tutoria foi transmitida aos alunos.

Entretanto, esse novo modelo mostra-se parcialmente satisfatório: a adesão aumenta, mas não da maneira esperada. As mudanças foram importantes, mas não suficientes.

Os alunos do internato continuam a ir menos aos encontros, os alunos dos outros anos continuam a ter seu tempo disputado entre diversas atividades extracurriculares ou aproveitam o tempo da Tutoria como tempo livre para descansar ou dormir. Fica evidente o quanto essas atividades (iniciação científica, ligas, procedimentos no hospital) são consideradas mais importantes ou mais interessantes para grande parte dos alunos. Assim como fica confirmado o quanto as características do curso médico diminuem a qualidade de vida dos estudantes e tem, especialmente em relação ao sono, um efeito deletério ${ }^{6}$.

A questão do mentoring informal também se apresentou entre as razões de menor adesão. Confirmando outros estudos, parece haver alunos que não desejam buscar ajuda ou trocar experiências com tutores, preferindo fazê-lo junto aos amigos, dentro de um contexto de mentoring informal. Cottrell e colegas ${ }^{19}$ mostraram em seu estudo preocupação particular com o fato de que em torno de $10 \%$ dos alunos não se sentem capazes de compartilhar problemas pessoais ou acadêmicos seja com seu tutor pessoal ou qualquer outro membro da equipe da escola. Em outro estudo, Chew-Graham e colegas ${ }^{21}$ também mostram que muitos alunos preferem procurar ajuda junto a um representante discente, mais do que junto a um tutor.

Depois das mudanças, o fator humano, traduzido em valores e características pessoais, manifesta-se mais claramente e, voltando a Grove ${ }^{17}$, é importante considerar o quanto a realidade humana é "caprichosa". Diz ele que, quanto mais nos aprofundamos na natureza humana, menos nós sabemos e conseguimos controlar e predizer.

Estudos em mentoring reconhecem o quanto é necessária a "química" entre tutores e alunos para que o encontro se torne significativo e produtivo ${ }^{22,23}$. Aqueles alunos que se referem a grupos de tutoria em que não encontraram afinidades com os colegas presentes parecem estar se referindo a esse ponto. $\mathrm{O}$ mesmo vale para a não afinidade com seus tutores. Importante lembrar que esses "pareamentos" são realizados de modo totalmente randomizado, em uma espécie de "encontro às escuras".

Programas de mentoring tentam formalizar algo que, em sua essência, é natural. Em outras palavras: as características de um mentoring espontâneo - interesse mútuo, identificação, atração - criam um dilema no desenvolvimento de um programa formal ${ }^{24}$. 
O desafio dos programas formais é buscar "mimetizar" processos interpessoais naturais por meio de oportunidades frequentes de encontro, treinamento, manejo de expectativas, treinamento e, por vezes, pareamento voluntário ${ }^{25}$.

Esses esforços foram também realizados pela coordenação do Programa Tutores e, quanto ao pareamento voluntário, é importante ressaltar que, embora os alunos não possam escolher seu tutor, na Tutoria FMUSP eles podem trocar de grupo sempre que acharem necessário, até encontrar um com o qual tenham afinidade.

Foi interessante observar, nesse sentido, que a questão do mentoring como "valor" se apresentou: se há alunos que valorizam esse tipo de experiência, existem também estudantes que consideram o mentoring pouco relevante, desinteressante e aborrecido. Menor interesse por atividades reflexivas, em geral, e pelo mentoring, em particular, tem sido destacado em outros estudos. A avaliação de Woessner e colegas ${ }^{20}$ mostra que há alunos que, embora registrados voluntariamente, ainda assim demonstram pouco interesse por esse tipo de atividade.

Nesse sentido, considerando a questão dos valores, no grupo de boa adesão, encontram-se alunos que, por suas características pessoais, reconhecem a importância da proposta e percebem os benefícios da troca de experiência. Eles gostam de tutores que, também por características pessoais, mostram-se hábeis, interessantes e interessados em fazer o mentoring acontecer de forma significativa.

Se características e valores pessoais permanecem como ingredientes fundamentais nas relações de mentoring, atraindo ou afastando pessoas da atividade, é importante lembrar que quando um programa desses é oferecido para todos os estudantes de uma escola, seu propósito, inevitavelmente, pode não ser estimulante para todos.

Este estudo deve ser compreendido, em sua natureza, como uma investigação que começou apenas a mapear esse terreno complexo - a relação entre tutor e aluno e a adesão deste à proposta do mentoring nas escolas médicas.

Entretanto, mesmo exploratório, sua força reside no fato de ser um dos poucos estudos, na área do mentoring, que aborda especialmente as razões de maior ou menor envolvimento com a atividade.

Como limitação, é necessário destacar que, mesmo sendo um estudo qualitativo, não focado em números e contagens, houve entre os respondentes, nos dois anos investigados, uma parcela muito pequena de alunos que não participavam ou participavam muito pouco da atividade.

Contudo, mesmo pouco representados, as razões dadas por esses alunos perante o "não ir" mostram-se congruentes com o cotidiano da formação médica atual: um cotidiano re- pleto de afazeres, marcado por uma competição acirrada e constante e que valoriza o fazer em detrimento ao refletir.

Conseguir mostrar e demonstrar aos estudantes que o mentoring é uma ferramenta importante na construção de sua identidade profissional e pessoal, com tanto valor para seu "currículo" quanto às demais atividades acadêmicas stricto sensu, é um grande desafio a ser enfrentado por todos que acreditam nessa proposta.

A natureza complexa e multifacetada da adesão dos alunos à atividade, evidenciada por este estudo, exige muito trabalho, comprometimento verdadeiro com a proposta, compreensão clara de seus objetivos e permanente reflexão para o desenvolvimento de estratégias criativas e viáveis dentro das estruturas das escolas médicas.

\section{REFERÊNCIAS}

1. Dyrbye LN, Thomas MR, Shanafelt TD. Systematic Review of Depression, Anxiety, and Other Indicators of Psychological Distress among U.S. and Canadian Medical Students. Acad Med. 2006;81:354-73.

2. Bligh J. Mentoring: an invisible support network. Med Educ. 1999;33:2-3.

3. Bellodi PL, Martins MA. Tutoria: Mentoring na formação médica. São Paulo: Casa do Psicólogo;2005.

4. Wolf TM. Stress, coping and health: enhancing well-being during medical school. Med Educ. 1994;28:8-17.

5. Coles C. Medicine and stress. Med Educ. 1994;28:3-4

6. Fiedler PT. Avaliação da Qualidade de Vida do estudante de Medicina e da influência exercida pela formação acadêmica São Paulo; 2008. Doutorado [Tese] - Universidade de São Paulo.

7. Spencer J. Physician, heal thyself: but not on your own, please. Med Educ. 2005;39:548-9.

8. Chew-Graham CA, Rogers A, Yassin N. 'I wouldn't want it on my CV or their records': medical students' experiences of help-seeking for mental health problems. Med Educ. 2003;37:873-880.

9. Roberts LW, Warner TD, Carte D, Frank E, Ganzini L, Lyketsos C. Caring for Medical Students as Patients: Access to Services and Care-seeking Practices of 1,027 Students at Nine Medical Schools. Acad Med. 2000; 75:272-7.

10. Hooper C, Meakin R, Jones M. Where students go when they are ill: how medical students access health care. Med Educ. 2005;39:588-93.

11. Flash DH, Smith MF, Smith WG, Glasser ML. Faculty mentors for medical students. J Med Educ. 1982;57:514-20.

12. Agar EM, Hauer KE. A Cross-sectional Descriptive Study of Mentoring Relashionships Formed by Medical Students. J Gen Intern Med. 2003;18:298-302. 
13. Colares MFA, Castro M, Peres CM, Passos ADC, Figueiredo JFC, Rodrigues MLV, et al. Group mentoring for junior Medical students: perceptions of mentees and mentors. Rev Bras Educ Med. 2009;3:670-5.

14. Rhodes J. Stand by me: the risks and rewards of mentoring today's youth. Cambridge: Harvard University Press; 2002.

15. Bellodi PL. Mentoring: to attend or not to attend. Oral Presentation. In: Association for Medical Education in Europe - AMEE Conference, 2006; Genoa, Italy, Anais. Genoa; 2006.

16. Bardin L. Análise de conteúdo. Lisboa: Edições 70; 1997.

17. Grove KH. EVALULEAD - A guide for shaping and evaluating leadership development programs. California: $\mathrm{Pu}-$ blic Health Institute; 2005.

18. Malik S. Students, tutors and relationships: the ingredients of a successful student support scheme. Med Educ. 2000;34:635-41.

19. Cottrell DJ, McCrorie P, Perrin F. The personal tutor system: an evaluation. Med Educ. 1994; 28:544-9.

20. Woessner R, Honold M, Stehle I, Stehr S, Steudel WI. Faculty mentoring programme - ways of reducing anonymity. Med Educ. 1998;32:441-3.

21. Chew-Graham CA, Rogers A, Yassin N. 'I wouldn't want it on my CV or their records': medical students' experiences of help-seeking for mental health problems. Med Educ. 2003;37:873-80.

22. Jackson VA, Palepu A, Szalacha L, Caswell C, Carr PL, Inui T. "Having the Right Chemistry": A Qualitative Study of Mentoring in Academic Medicine. Acad Med. 2003;78:328-34.
23. Reilly T, Roberts KA, Harrow S. Mentor/Mentee: A Delicate Balance of Chemistry. DCMA Communicator. 2005;13-17.

24. Allen TD, Eby LT, Lentz E. Mentorship behaviors and mentorship quality associated with formal mentoring programs: closing the gap between research and practice. J Appl Psychol. 2006;91:567-78.

25. Ragins BR, Cotton JL. Mentor functions and outcomes: a comparison of men and women in formal and informal mentoring relationships. J Appl Psychol. 1999;84:529-50,

\section{CONTRIBUIÇÃO DOS AUTORES}

Patrícia Lacerda Bellodi contribuiu na determinação do tema e objetivos do estudo, revisão de literatura, definição metodológica, análise dos dados, discussão dos resultados e redação final do artigo. Rachel Chebabo e Silvia Abensur contribuíram na coleta e análise dos dados. Milton de Arruda Martins contribuiu na discussão dos resultados e redação final do artigo.

\section{CONFLITO DE INTERESSES}

Declarou não haver

\section{ENDEREÇO PARA CORRESPONDÊNCIA}

Patrícia Lacerda Bellodi

Rua Dona Luiza Júlia, 12, apto 62

Itaim Bibi - São Paulo

CEP. 04542-020 SP

E-mail: ptbellodi@uol.com.br 